www.nature.com/pj

\title{
Hyperbranched poly(ether sulfone)s: preparation and application to ion-exchange membranes
}

\author{
Masa-aki Kakimoto, Stephen J Grunzinger ${ }^{1}$ and Teruaki Hayakawa
}

Hyperbranched polymers possess unique characteristics such as low viscosity, high solubility in organic solvents and a high degree of functionality at the terminal position. However, hyperbranched polymers also possess weak mechanical properties. In this study, hyperbranched poly(ether sulfone)s (HBPES) possessing sulfonic acid moieties at the terminal position were prepared by reacting electrophilic sulfonium ions with electron-rich benzene rings from two kinds of $A B_{2}$ monomers.

To address the weakness of HBPES, hybrid materials containing linear and hyperbranched PES were investigated. Linear and hyperbranched multiblock copolymers were successfully prepared by reacting oligomeric linear $P E S$ and $A B_{2}$ monomers.

From the multiblock copolymers, linear and hyperbranched PES blends were prepared and applied as ion-exchange membranes for fuel cells. Films containing various ratios of linear and hyperbranched PES terminated by sulfonyl chloride groups were prepared via casting from a solution of DMAc. The results indicated that tethers between linear and hyperbranched polymers were important for controlling the size of the phases and for preventing the dissolution of HBPES in water; thus, linear and hyperbranched polymers were crosslinked by simply heating blends of both films. Finally, hybrid films containing sulfonic acid groups were obtained by hydrolyzing the sulfonyl chloride moieties. The resultant films showed ion-exchange capacities that were comparable to that of a Nafion 117 membrane (Dupont, Tokyo, Japan).

Polymer Journal (2010) 42, 697-705; doi:10.1038/pj.2010.70

Keywords: $\mathrm{AB}_{2}$ monomers; electrophilic reaction; fuel cell; hyperbranched polymers; ion-exchange membrane; linear hyperbranched block copolymers

\section{INTRODUCTION}

Hyperbranched polymers are dendritic macromolecules that have a systematic branching structure. The concept of 'dendritic macromolecules' was introduced by Tomalia in $1985 .{ }^{1}$ Compared with linear polymers, dendritic macromolecules are more amorphous, and are usually soluble in organic solvents because of their highly branched structures. Dendritic macromolecules can be classified as dendrimer or hyperbranched polymer. Dendrimers have a precise chemical structure, and hyperbranched polymers consist of a mixture of polymers with different molecular weights.

Hyperbranched polymers have attracted a considerable amount of attention because of their ease of synthesis, degree of functionality and material properties. ${ }^{2-4}$ As shown in Figure 1, the structure of hyperbranched polymers is similar to that of dendrimers. Moreover, hyperbranched polymers are highly soluble, possess many functional groups and have a rigid structure (that is, low entropy). Although many synthetic steps are required to produce multigenerational dendrimers, hyperbranched polymers can be easily prepared in a single reaction vessel from $\mathrm{AB}_{\mathrm{x}}$-type monomers, where the monomer contains a single A group and multiple (x) B groups.
Recently, we prepared hyperbranched polymers, such as aromatic polyamides, ${ }^{5-18}$ polyimides, ${ }^{19-24,15,25}$ polyesters, ${ }^{26}$ polysiloxanes, ${ }^{27,28}$ poly(benzoxazole)s, ${ }^{29-33}$ poly(triphenylamine), ${ }^{34} \mathrm{PES}^{35-39}$ and poly (siloxysilane), ${ }^{40-45}$ from $\mathrm{AB}_{2}$ type monomers, and investigated their mechanical properties. Moreover, to synthesize polyamides, ${ }^{46}$ polyimides ${ }^{47,23,48}$ and polyphthalocyanines, ${ }^{49-57}$ we developed a novel $\mathrm{A}_{2}+\mathrm{B}_{3}$ method.

The focus of this study was to prepare hyperbranched poly(ether sulfone)s (HBPES) with sulfonic acid groups at the terminal position and to apply these polymers to ion-exchange membranes. In general, hyperbranched polymers contain a significant number of end groups. ${ }^{58}$ In HBPES, the number of sulfonic acid end groups is equal to the degree of polymerization; thus, HBPES contains a hydrophobic core and a hydrophilic shell of sulfonic acid end groups. Owing to the structural characteristics of HBPES, these polymers possess a suitable path for proton conduction and may have potential for applications such as ion-exchange membranes.

In this paper, the preparation and properties of HBPES is described in detail. As hyperbranched polymers have poor mechanical properties, block copolymers of linear and HBPES were prepared to improve

Department of Organic and Polymeric Materials, Tokyo Institute of Technology, Tokyo, Japan

${ }^{1}$ Current address: Nitto Denko Technical Corporation, 501 Via Del Monte, Oceanside, CA 92057, USA.

Correspondence: Professor M Kakimoto, Department of Organic and Polymeric Materials, Tokyo Institute of Technology, S8-26, 2-12-1, Ookayama, Meguro-ku, Tokyo 152-8550, Japan.

E-mail: mkakimot@o.cc.titech.ac.jp

Received 11 June 2010; revised and accepted 30 June 2010 
the mechanical properties of the material and to prepare ion-exchange membranes.

\section{PREPARATION OF HBPES}

Hyperbranched polymers are typically prepared by self-condensation of $\mathrm{AB}_{\mathrm{x}}$ monomers. For instance, as shown in Figure 2, 3,5-diaminobenzoic acid contains one carboxylic acid (A) and two amines (B); thus, hyperbranched polyamides can be produced via the self-condensation of 3,5-diaminobenzoic acid to form amide bonds between $\mathrm{A}$ and $\mathrm{B}$.

During polymerization of HBPES, the electrophilic sulfonium ion reacts with the electron-rich benzene ring. As shown in Equation (1), HPES 2 was prepared by self-condensation of 2,6-bis( $p$-sodium sulfophenoxy) benzonitrile $\underline{1}$, which was obtained via the condensation of sodium $p$-hydroxybenzene sulfonate and 2,6-dichloro benzonitrile in the presence of potassium carbonate. ${ }^{35}$ The polycondensation reaction was conducted at $140{ }^{\circ} \mathrm{C}$ for $24 \mathrm{~h}$ in the

presence of a mixture of phosphorus pentoxide and methane sulfonic acid, which was used as the condensing agent, as well as the solvent. ${ }^{59}$ The resulting mixture was poured into water and dialyzed to remove low-molecular-weight materials. HPES was isolated by freeze-drying and was obtained in $92 \%$ yield. Polymer 2 was soluble in DMSO and water.

Ueda and Matsumoto ${ }^{60}$ prepared HBPES by a different method, as shown in Equation (2). Specifically, resorcinol was reacted with sodium $p$-fluorobenzenesulfonate in the presence of potassium carbonate to produce $4,4^{\prime}$-( $m$-phenylenedioxy) bis(benzenesulfonic acid disodium salt), which was subsequently treated with phosphorus oxychloride to afford monomer $\underline{3}$. Polycondensation of $\underline{3}$ was conducted in nitrobenzene in the presence of $1 \mathrm{wt} \% \mathrm{FeCl}_{3}$. The polymerization proceeded smoothly at $120^{\circ} \mathrm{C}$ for $3 \mathrm{~h}$, providing hyperbranched polymer 4 with a maximum number-average molecular weight of 35700 and a solution viscosity of $0.1-0.2$ per $100 \mathrm{ml} \mathrm{g}^{-1}$, as determined by gel-permeation chromatography (GPC) with polystyrene standards.

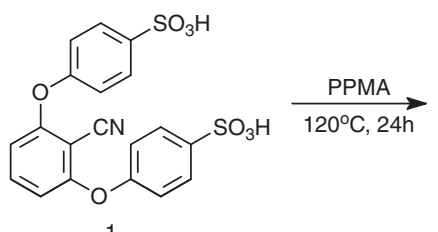

1

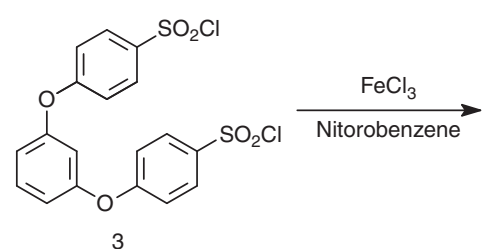

$\underline{3}$

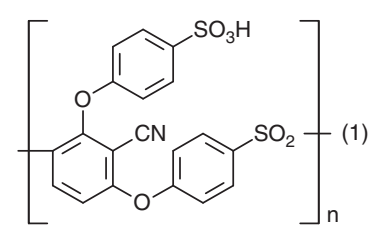

$\underline{2}$<smiles>O=S(=O)(Cl)c1ccc(Oc2cccc(Oc3ccc(S(=O)(=O)Cl)cc3)c2)cc1</smiles>

$\underline{4}$

Terminal

Figure 1 Hyperbranched polymers.

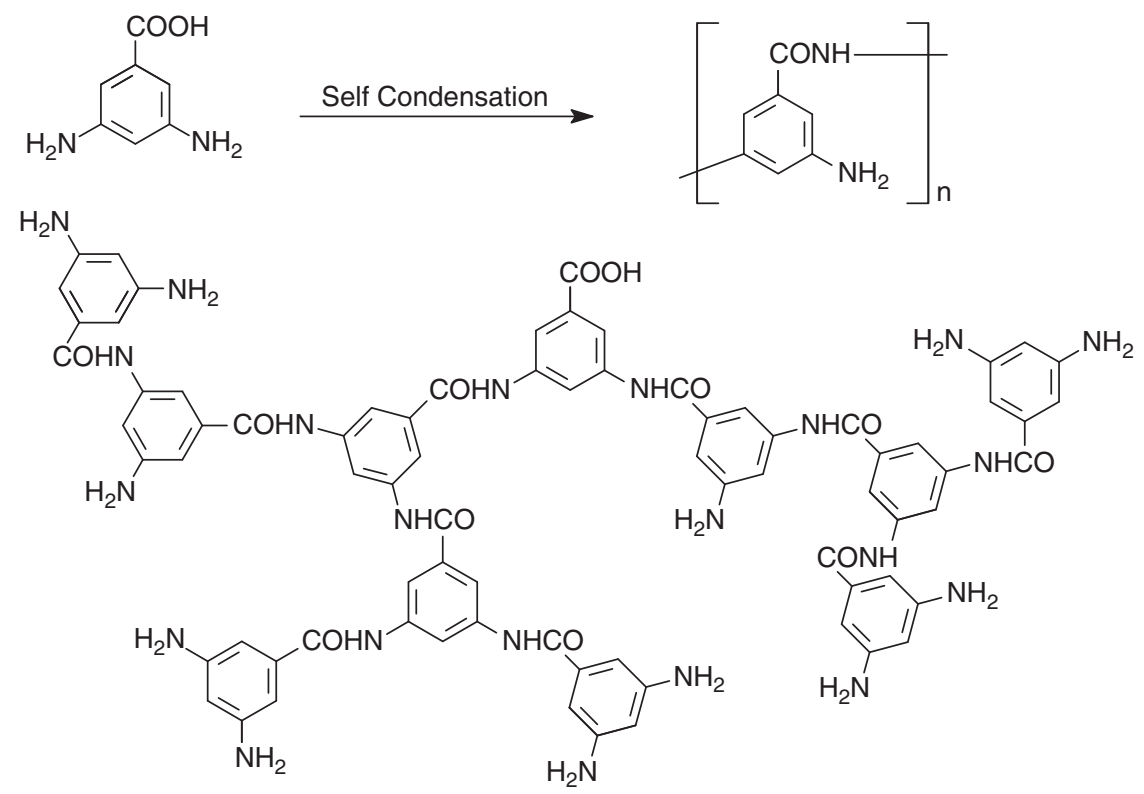

Figure 2 Typical synthesis of hyperbranched polymers. 


\section{PREPARATION OF HYPERBRANCHED-LINEAR PES MULTIBLOCK COPOLYMERS}

The ease of preparation of hyperbranched polymers has led to their incorporation into many copolymers. ${ }^{39,61,62}$ The copolymerization of hyperbranched monomers as the random component of the block copolymer results in controlled branching and enhanced linear polymer properties. ${ }^{63,64}$ Hyperbranched polymers are frequently used as the core of core-shell block copolymers, where the shell block is grown from the functional groups of the hyperbranched polymer. ${ }^{65-67}$ Hyperbranched polymers have also been grown from linear polymers to form diblock, ${ }^{68}$ gridlock $^{69,70}$ and graft copolymers. ${ }^{41,71,72}$ Hyperbranched polymers have also been prepared from one or more oligomeric monomers to yield products that have additional flexibility. ${ }^{73-76}$ Although the concentrated functionality of a dense hyperbranched polymer is desirable in applications such as fuel cell membranes, additional entanglements are necessary to avoid poor blend compatibility and leaching.

To prepare hyperbranched polymers with a densely functionalized core and a sufficient number of entanglements, polymeric linear blocks were incorporated via a two-step, single-pot approach that generates the linear block before the addition of hyperbranched monomers. In addition to the facile single-pot synthetic procedure, another advantage of the proposed architecture is that the ratio of linear to hyperbranched blocks can be easily controlled. In the synthesis of diblock and triblock copolymers, the duration of the reaction and the size of the blocks control the ratio of the sizes of the blocks because each block is prepared separately. Moreover, higher molecular weight fractions from the same reaction have a different linear to hyperbranched molar ratio. However, with linear-hyperbranched multiblock architectures, both components remain reactive through the reaction, and the molar ratio is determined by the initial concentration of hyperbranched monomers. Thus, although the molecular weight increases over time, the ratio of the sizes of the blocks is the same, regardless of the molecular weight of the polymer. A constant block size ratio was necessary to improve the performance of blend films for fuel cell membranes. ${ }^{38}$ Homo-hyperbranched polymers form large continuous phases that are suitable for proton conductivity; however, the size of the phase and the solubility of the hyperbranched polymer lead to rapid material loss and performance deficiencies. Adding a structural component to increase the compatibility of the blend reduces the size of the phase and increase the amount of material retain by the membrane.

For the linear block of the block copolymer, a repeating unit of $p$-phenoxyphenylsulfone was targeted because of its structural similarity to HBPES and the presence of a sulfone group on the phenyl ring, which deactivates the linear chain toward electrophilic addition during the polymerization of the hyperbranched polymer. If the phenyl rings of the linear block were susceptible to electrophilic addition, the reaction would generate a crosslinked network rather than a soluble polymer. The $\mathrm{AB}$ monomer 4-(phenoxy)benzenesulfonyl chloride was synthesized via the sulfonation of diphenylether with concentrated sulfuric acid and acetic anhydride. The conversion of the sulfonate to sulfonyl chloride was accomplished by refluxing in $\mathrm{POCl}_{3}$. The nuclear magnetic resonance (NMR) spectrum of the resulting monomer was consistent with the formation of mono-sulfonated diphenyl ether.

A plot of the molecular weight versus time was generated for the polymerization of the $\mathrm{AB}$ monomer. The $\mathrm{AB}$ monomer was polymerized in nitrobenzene $(20 \mathrm{wt} \%$ monomer $)$ at $130{ }^{\circ} \mathrm{C}$ in the presence $\mathrm{FeCl}_{3}(1.6 \mathrm{~mol} \%)$, which was used as the catalyst. The product was recovered by precipitation from methanol and the molecular weight was determined by GPC as a function of time (Table 1). The GPC results indicated that the molecular weight and polydispersity of the polymer increased over time, which is typical for condensation polymerizations. In general, the DSC thermograms indicated a single $T \mathrm{~g}$ between 133 and $154^{\circ} \mathrm{C}$. In addition to nitrobenzene and DMF, the linear polymers were also soluble in dimethylformamide, tetrahydrofuran, dimethylsulfoxide, acetone and chloroform, and they were slightly soluble in toluene and ethyl acetate. Alternatively, the polymers were completely insoluble in hexanes and ether. The NMR spectra of the linear products indicate primarily para-addition of the sulfonyl chloride, along with $12-16 \%$ ortho-addition. Thus, the results indicated that a linear polymer with one terminal phenoxy (A) group, one terminal sulfonyl chloride (B) group and an inert chain was formed. As a result, crosslinking in subsequent polymerization was prevented and the formation of a linear-hyperbranched multiblock architecture was achieved.

The polymerization of $4,4^{\prime}$-( $m$-phenylene-dioxy)bis(benzenesulfonyl chloride) 3 for the generation of hyperbranched polymers has previously been reported by Ueda and Matsumoto. ${ }^{60}$ Polymers with a multiblock linear-hyperbranched architecture were generated by the addition of $\mathrm{AB}_{2}$ monomers to the reaction mixture after a specified duration (either $15 \mathrm{~min}$ or $1 \mathrm{~h}$ ) of $\mathrm{AB}$ polymerization. A 19:1 molar ratio of the $\mathrm{AB}_{2}$ monomers to the $\mathrm{AB}$ macromonomer was employed, and the molecular weight of the linear block was determined from the polymerization time (Table 1 ). The overall $\mathrm{AB}_{2}$ : $\mathrm{AB}$ molar feed ratio for the entire procedure was 1.35 for $15 \mathrm{~min}$ and 0.39 for $1 \mathrm{~h}$ of linear block polymerization (Table 2). Additional catalyst and solvent were added to maintain a catalyst concentration of $1.6 \mathrm{~mol} \%$ and a monomer concentration of $20 \mathrm{wt} \%$, respectively. To achieve hyperbranched polymerization, the reaction was continued for 6 or $12.5 \mathrm{~h}$ and the products were precipitated from methanol. To indicate the duration of linear and hyperbranched polymerization, the products of this two-step process are generically referred to as LxHB. The aforementioned synthetic procedures are summarized in Scheme 1.

The DSC thermograms displayed a single $T$ g around $200^{\circ} \mathrm{C}$ for all LxHB products, which was significantly higher than the $T g$ of the

Table 1 Linear poly(ether sulfone) molecular weight versus time

\begin{tabular}{lccccc}
\hline ID no. & Linear Rxn time & $\mathrm{Mw}(\mathrm{gmol})^{\mathrm{a}}$ & $\mathrm{PDI}$ & $\mathrm{Tg}\left({ }^{\circ} \mathrm{C}\right)^{\mathrm{b}}$ & Frac. 1,2-addition \\
\hline 1 & $15 \mathrm{~min}$ & $3.5 \mathrm{k}$ & 1.57 & 134 & 0.12 \\
2 & $1 \mathrm{~h}$ & $12.4 \mathrm{k}$ & 1.85 & 142 & 0.13 \\
3 & $3 \mathrm{~h}$ & $21.5 \mathrm{k}$ & 2.48 & 141 & 0.15 \\
4 & $10 \mathrm{~h}$ & $57.5 \mathrm{k}$ & 2.84 & 154 & 0.16
\end{tabular}

Abbreviations: Frac., fraction; GPC, gel permeation chromatography; PDI, polydispersity index; Rxn, reaction.

aCalculated by DMF GPC

betermined by DSC.

'Fraction of 1,2-sulfone addition versus 1,4-sulfone addition.

Table 2 Linear-hyperbranched (LxHB) reaction products

\begin{tabular}{ccccccc}
\hline Linear & & & & & \\
ID & $\begin{array}{c}\text { reaction } \\
\text { no. }\end{array}$ & $\begin{array}{c}\text { Hyperbranched } \\
\text { reaction time }\end{array}$ & $\begin{array}{c}\mathrm{Mw} \\
\left(\mathrm{gmol}^{-1}\right)^{\mathrm{a}}\end{array}$ & $\mathrm{PDI}$ & $\begin{array}{c}\mathrm{Tg} \\
\mathrm{ratio}^{\mathrm{b}}\end{array}$ & $\left({ }^{\mathrm{C}}\right)^{\mathrm{c}}$ \\
\hline 5 & $15 \mathrm{~min}$ & $6 \mathrm{~h}$ & $26.6 \mathrm{k}$ & 1.34 & 1.35 & 206 \\
6 & $15 \mathrm{~min}$ & $12.5 \mathrm{~h}$ & $34.6 \mathrm{k}$ & 1.15 & 1.35 & 203 \\
7 & $1 \mathrm{~h}$ & $6 \mathrm{~h}$ & $53.5 \mathrm{k}$ & 1.84 & 0.39 & 216 \\
8 & $1 \mathrm{~h}$ & $12.5 \mathrm{~h}$ & $145.6 \mathrm{k}$ & 1.92 & 0.39 & 201
\end{tabular}

Abbreviations: GPC, gel permeation chromatography; PDI, polydispersity index.

aCalculated by DMF GPC

${ }^{\mathrm{b}} \mathrm{AB}_{2}: \mathrm{AB}$ mole ratio calculated from monomer feed ratio.

${ }^{\circ}$ Calculated by DSC. 


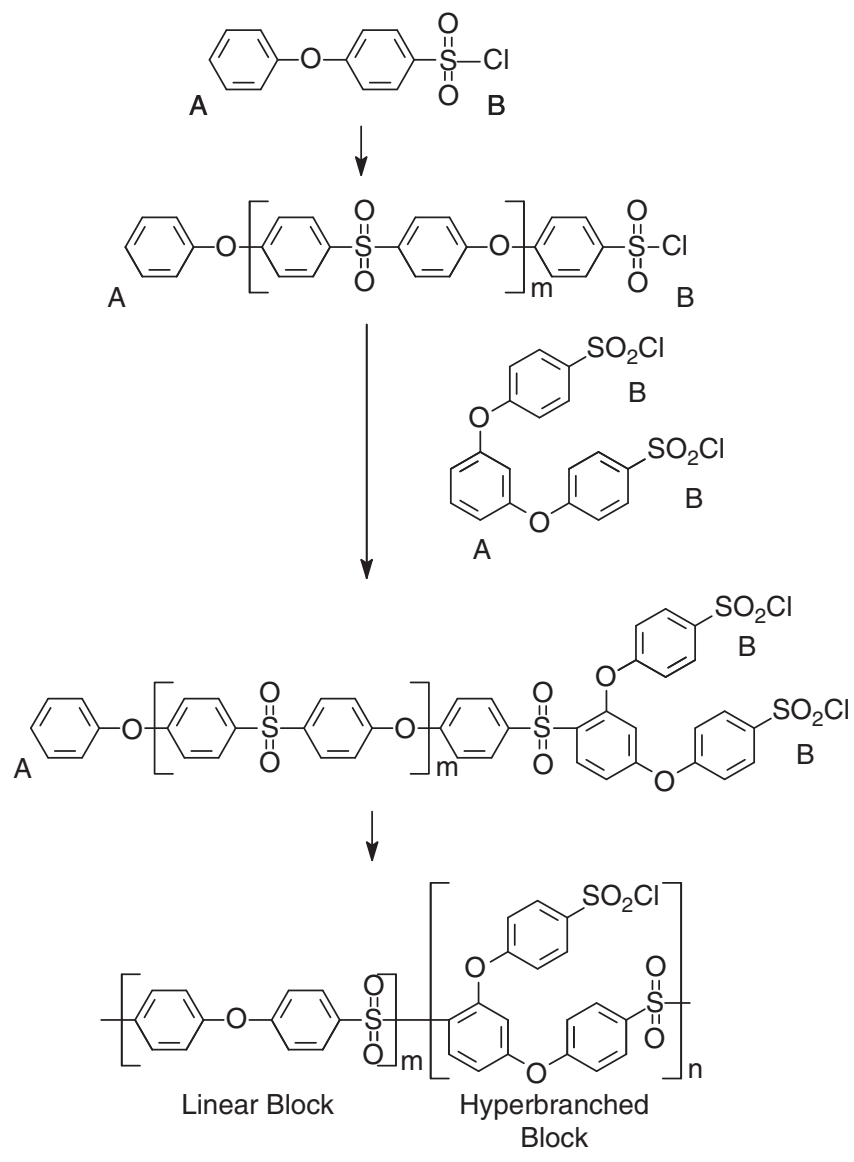

Scheme 1 Reaction scheme to generate linear-hyperbranched multiblock copolymers. A and B denote the electron-rich aromatic ring and electrophile, respectively. Dentritic and terminal repeating units of hyperbranched block not shown.

linear homopolymers $\left(133-154^{\circ} \mathrm{C}\right)$. The $\mathrm{Tg}$ of a homo-hyperbranched polymer with a molecular weight of $30 \mathrm{k}$ is $>250^{\circ} \mathrm{C}$; however, a homo-hyperbranched polymer with a molecular weight of $8.4 \mathrm{k}$ has a $\mathrm{Tg}$ of $\sim 181{ }^{\circ} \mathrm{C}$ The presence of a single $\mathrm{Tg}$ indicated that a single product formed with little to no phase separation. Similar to homo-hyperbranched polymers, LxHB products 5 and 6 did not possess film forming properties. LxHB products 7 and 8 did form films, but were too brittle to investigate the mechanical and phase properties.

From the GPC and NMR data, we deduced that a linear-hyperbranched multiblock architecture had formed. The formation of homopolymers was not indicated by the GPC data; however, the NMR spectra suggested that the phenoxy end group of the linear polymer were consumed. The full consumption of the end groups was not surprising because excess sulfonyl chlorides were present in the $\mathrm{AB}_{2}$ monomer. The connectivity of the sulfonyl chloride group of the linear polymer was unclear because of its low concentration and degenerate NMR position with hyperbranched sulfonyl chlorides. However, the reactivity of the sulfonyl chlorides should be similar because both functional groups are para to a phenolic ether. The use of alternate core monomers for hyperbranched polymers has been previously demonstrated; thus, the reaction of the $B$ group of the linear macromonomer, which possess similar reactivity to the $\mathrm{B}$ group of the $\mathrm{AB}_{2}$ monomer, was assumed to be based on statistical probability.

The overall reaction process is illustrated in Scheme 1. Initially, only linear polymer growth occurs because only $\mathrm{AB}$ monomer is present.

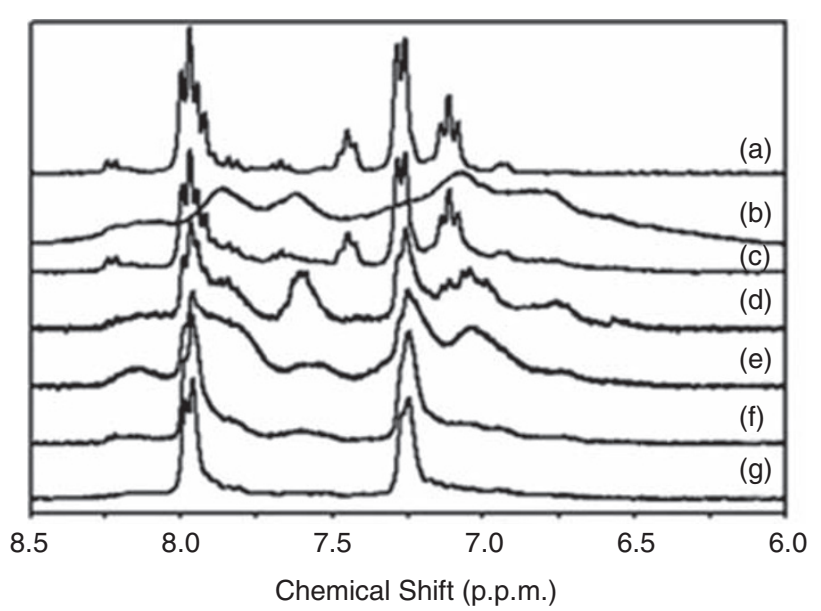

Figure 3 NMR spectra of (a) homo-linear PES, (b) homo-HBPES, (c) blend of linear and hyperbranched PES, (d) LxHB $15 \mathrm{~min} \times 6 \mathrm{~h}$, (e) LxHB $15 \mathrm{~min} \times 12.5 \mathrm{~h}$, (f) LxHB $1 \mathrm{~h} \times 6 \mathrm{~h}$ and (g) LxHB $1 \mathrm{~h} \times 12.5 \mathrm{~h}$. Spectra were acquired in dimethylsulfoxide (DMSO)-d6 using a JOEL-JNM-AL-300 spectrometer (JEOL, Tokyo, Japan). Blend (c) contains a 1:1 ratio of linear and hyperbranched PES (wt/wt), which is compositionally equivalent to products $(f)$ and $(g)$.

When $\mathrm{AB}_{2}$ monomer is added to the reaction mixture, the linear polymer reacts with the $\mathrm{AB}_{2}$ monomer at both ends of the chain. Owing to the large molar excess of the $\mathrm{AB}_{2}$ monomer, it is unlikely that further linear addition occurs. The reaction of an $\mathrm{AB}$ linear block with an $\mathrm{AB}_{2}$ monomer consumes one $\mathrm{A}$ unit and one $\mathrm{B}$ unit. As a result, one $A$ unit and two $B$ units remain, which is essentially a large $\mathrm{AB}_{2}$ monomer. Therefore, because the linear blocks neither subtract functionality nor induce crosslinking, the polymerization behaves similarly as a typical hyperbranched polymerization. However, the main type of polymer that forms will be the condensation polymer of the $\mathrm{AB}_{2}$ monomer creating its own block. Eventually, two polymer units containing a linear block will condense, and linear blocks will become separated by a region of hyperbranched polymer. Growing polymer units will continue to combine, generating a polymer with multiple linear and hyperbranched blocks.

The number of linear and hyperbranched sections, as well as the average size of the hyperbranched block, was calculated from the peaks in NMR spectra (Figure 3). In the NMR spectra of LxHB, the region from 8.0 to 7.9 p.p.m and 7.3 to 7.2 p.p.m. was attributed to the protons on the linear block derived from para-addition. The remaining portion of the aromatic region was attributed to the hyperbranched polymer and the ortho-addition product. However, as the ortho-addition product accounted for $13 \%$ of the total addition products, the relative areas of the peaks were adjusted accordingly. The area of both peaks was normalized to the number of protons in the repeating unit (eight for the linear polymer and eleven for the hyperbranched polymer), and the molar ratio of $\mathrm{AB}_{2}: \mathrm{AB}$ units in the polymer was calculated (Table 3 ). The results indicate that the molar ration of $\mathrm{AB}_{2}: \mathrm{AB}$ units was nearly identical to the initial molar ratio of monomers, which suggests that the $\mathrm{AB}$ macromonomer and the $\mathrm{AB}_{2}$ monomer possess similar reactivity. Furthermore, the average number of $\mathrm{AB}_{2}$ repeating units per hyperbranched block (Table 3) was obtained from the $\mathrm{AB}_{2}: \mathrm{AB}$ ratio and the molecular weight of the linear polymer (Table 2 ). For all of the copolymers, the ratio of $\mathrm{AB}_{2}$ units to $\mathrm{AB}$ macromonomer was equal to 20, which is slightly higher than the initial 19:1 molar ratio. Moreover, the average molecular weight of the hyperbranched block in the LxHB 
Table 3 Calculation of hyperbranched block size

\begin{tabular}{cccccc}
\hline $\begin{array}{l}\text { ID } \\
\text { no. }\end{array}$ & $\begin{array}{c}A B_{2}: A B N M R \\
\text { ratio }\end{array}$ & $\begin{array}{c}L \mathrm{Mw} \\
\left(\mathrm{g} \mathrm{mol}^{-1}\right)^{\mathrm{a}}\end{array}$ & $\begin{array}{c}A B_{2} \text { repeat } \\
\text { units }^{\mathrm{b}}\end{array}$ & $\begin{array}{c}H B \mathrm{Mw} \\
\left(\mathrm{g} \mathrm{mol}^{-1} \mathrm{c}\right.\end{array}$ & $\begin{array}{c}\text { No. of } L-H B \\
\text { pairs }^{\mathrm{d}}\end{array}$ \\
\hline 5 & 1.33 & $3.5 \mathrm{k}$ & 20.4 & $8.6 \mathrm{k}$ & 2.2 \\
6 & 1.41 & $3.5 \mathrm{k}$ & 21.6 & $9.1 \mathrm{k}$ & 2.7 \\
7 & 0.38 & $12.4 \mathrm{k}$ & 20.5 & $8.7 \mathrm{k}$ & 2.5 \\
8 & 0.37 & $12.4 \mathrm{k}$ & 20.0 & $8.4 \mathrm{k}$ & 7.0 \\
\hline
\end{tabular}

Abbreviations: GPC, gel permeation chromatography; HB, hyperbranch; L, linear; NMR, nuclear magnetic resonance.

a Molecular weight of linear block from Table 2 used to calculate average size of hyperbranched block.

${ }^{b}$ Calculated average number of $\mathrm{AB}_{2}$ repeating units per hyperbranched block.

'Calculated average hyperbranched molecular weight based on number of repeat units.

dNumber of theoretical linear-hyperbranched block pairs to satisfy both GPC molecular weight and NMR integration ratio.

products was $8700 \mathrm{~g} \mathrm{~mol}^{-1}$ (Table 3 ). These results are in good agreement with the $T \mathrm{~g}$ of the low-molecular-weight hyperbranched homopolymers.

The average number of linear blocks per polymer chain can be estimated using an $\mathrm{L}-\mathrm{HB}$ pair as an abstract means of approximation. An $\mathrm{L}-\mathrm{HB}$ pair is defined as a linear block and a hyperbranched block with a molar ratio that matches the calculated NMR ratio. By dividing the molecular weight of the product by the molecular weight of the $\mathrm{L}-\mathrm{HB}$ pair, the number of linear blocks can be obtained. However, the major or preferential block connectivity cannot be constructed from the NMR data. Moreover, the molecular structures derived from these architectures will be different from those of diblock, dumbbell triblock and core-shell linear-hyperbranched polymers.

The materials were evaluated as blends in fuel cell membranes; however, the proposed method for the generation of this type of polymer architecture is applicable to any hyperbranched polymerization of linear chains with $A B$ terminal groups that match the chemistry of $A B_{x}$.

\section{HYPERBRANCHED-LINEAR PES BLEND FILMS FOR PROTON-EXCHANGE MEMBRANES}

The development of fuel cells for commercial applications has been hindered by the synthesis of suitable materials, including those for proton-exchange membrane. ${ }^{38,77-79}$ The current membrane used for many fuel cell assemblies is Nafion, a sulfonated fluoropolymer, and many materials that are currently being developed mimic the basic architecture of a continuous polymer electrolyte. ${ }^{78,80}$ Many materials with high proton conductivities have been synthesized; however, the majority of these materials also have high water uptake and fuel crossover because of the mechanism of proton conduction in continuous polyelectrolytes. ${ }^{81,80}$ High water uptake impedes water management at the required operating temperatures, and fuel crossover diminishes power output.

The mechanism of proton conduction in Nafion and other protonexchange membranes involves the formation of water-filled pores and channels within the film ${ }^{82,83}$ and proton conduction occurs through a hopping mechanism. The pores are generated by the rearrangement of polymer chain, which bring hydrophilic sulfonic acid groups into contact with water and allow hydrophobic segments to migrate away. ${ }^{83}$ However, the mobility of the polymer chains is problematic at elevated temperatures. The management of liquid water, which is critical for proton hopping, is more difficult as the temperature approaches the boiling point. Moreover, at increased temperature, the linear chains begin to coil, destabilizing the pores. ${ }^{84,85}$

Hyperbranched polymers have very little entropy; thus, entropic coiling, which destabilizes linear polymers is not present in hyperbranched polymers. To overcome the mechanical deficiencies of hyperbranched polymers and to access the multitude of functional groups that they contain, blends of HBPES bearing sulfonic acid end groups were fabricated, and a linear PES was added to serve as a structural support. These types of polymer blends have shown potential as fuel cell membranes. ${ }^{86}$ Blended films undergo spinodal decomposition into bicontinuous phases, and the high concentration of acid groups from the hyperbranched polymer promote proton conduction in one phase, while the mechanical robustness of the linear polymer is retained in the other phase.

\section{Preparation of hyperbranched-linear PES-blended films}

Linear poly(ether ether ether sulfone) were prepared via nucleophilic aromatic substitution of 4,4'-di(chlorophenyl)sulfone with $4,4^{\prime}$-di (hydroxyphenyl)ether. ${ }^{86}$ Typically, the purified reaction product possessed a viscosity of 0.40 in DMAc. GPC analysis in DMF indicated that the molecular weight $(\mathrm{Mw})$ of the polymer was $42600 \mathrm{~g} \mathrm{~mol}^{1}$ and the polydispersity index was 1.98 . The ${ }^{1} \mathrm{H}$ NMR spectrum revealed that a doublet was located at 7.88 p.p.m. (ortho-sulfone protons) and an unresolved multiplet appeared at 6.78-7.16 p.p.m. The doublet and unresolved multiplet integrated to a 1:3 ratio, which is consistent with linear poly(ether ether ether sulfone).

HBPES were prepared by Freidel-Craft acylation using $\mathrm{FeCl}_{3}$ as the catalyst (Equation (2)). ${ }^{60} \mathrm{GPC}$ analysis indicated that the molecular weight $(\mathrm{Mw})$ of the polymer was $27900 \mathrm{~g} \mathrm{~mol}^{-1}$ and the polydispersity index was 1.54 . The ${ }^{1} \mathrm{H}$ NMR spectrum revealed several, broad, unresolved peaks between 6.6 and 8.3 p.p.m. The Fourier-transform infrared spectrum contained a peak at $1376 \mathrm{~cm}^{-1}$, which is consistent with the $\mathrm{S}=\mathrm{O}$ stretching of sulfonyl chloride.

Films were prepared by casting from a solution of the hyperbranched sulfonyl chloride and $20 \mathrm{wt} \%$ linear polymers in DMAc. The solutions also contained a small amount of $\mathrm{FeCl}_{3}$ to catalyze the reaction between hyperbranched end groups with electron-rich aromatic rings of the linear polymer. The linear polymer is very sensitive to protic moieties in solution; thus, the sulfonyl chloride form of the hyperbranched polymer was used to allow for a greater weight percent of hyperbranched polymer in the coating solution.

The thickness of the coating was controlled by a doctor blade with a $125-\mu \mathrm{m}$ gap. The cast films were dried in vacuo at $150^{\circ} \mathrm{C}$ to remove the DMAc. After drying, the thickness of the films was typically $12 \%$ of the coating thickness (Table 4). The films were optically transparent after drying; however, the film prepared with $30 \mathrm{wt} \%$ hyperbranched polymer was hazy because of a significant amount of phase separation.

Optical microscope images of the dried films indicated a phase separation that was spinodal-like in appearance. Films cast with 10 and $20 \mathrm{wt} \%$ hyperbranched polymer exhibited a uniform spinodal phase structure. Alternatively, films cast with $30 \mathrm{wt} \%$ hyperbranched polymer displayed, a number of spherical features; however, spinodallike features were still apparent. The haziness of the film could also be attributed to the presence of spherical phases. These results indicated that films prepared at or above $30 \mathrm{wt} \%$ hyperbranched polymers have access to a nonspinodal phase separation pathway.

To prevent leaching of water-soluble, sulfonic acid-terminated hyperbranched polymers from the membrane, the linear polymer was covalently attached to the membrane via Freidel-Craft aromatic sulfonation, which was used to generate the sulfonyl chloride-terminated hyperbranched polymer (Scheme 2). Poly(ether ether ether sulfone) possesses electron-rich aromatic rings similar to the A-ring of the $\mathrm{AB}_{2}$ monomer; however, $\mathrm{FeCl}_{3}$ is not a typical catalyst for Freidel-Craft aromatic sulfonation in DMAc or in the solid state. Attempts to polymerize $\mathrm{AB}_{2}$ monomer in DMAc with $\mathrm{FeCl}_{3}$ did not yield the desired product. However, after phase formation, the 
Table 4 Thickness, water uptake and resolubility in DMAc

\begin{tabular}{lcccc}
\hline$H B w t \%$ & $\begin{array}{c}\text { Process } \\
\text { conditions }\end{array}$ & $\begin{array}{c}\text { Thickness } \\
(\mu \mathrm{m})\end{array}$ & $\begin{array}{c}\text { Water } \\
\text { luptake }\end{array}$ & $\begin{array}{c}\text { DMAc } \\
\text { solubility }\end{array}$ \\
\hline 0 & Dried & 17 & 1.005 & $\mathrm{Y}$ \\
0 & Cured & 17 & 1.021 & $\mathrm{Y}$ \\
10 & Dried & 12 & 1.020 & $\mathrm{Y}$ \\
10 & Cured & 11 & 1.070 & $\mathrm{~N}$ \\
20 & Dried & 14 & 1.066 & $\mathrm{Y}$ \\
20 & Cured & 10 & 1.032 & $\mathrm{~N}$ \\
30 & Dried & 9 & 1.025 & $\mathrm{Y}$ \\
30 & Cured & 10 & 1.034 & $\mathrm{~N}$ \\
Nafion 117 & - & 205 & 1.180 & - \\
\hline
\end{tabular}

Abbreviation: $\mathrm{HB}$, hyperbranch.

All films were dried at $150^{\circ} \mathrm{C}$, whereas cured films were also heated at $220^{\circ} \mathrm{C}$. Thickness measurements are the average of four measurements over three samples ( 12 total). Water uptake was calculated after $16 \mathrm{~h}$ of water immersion and is relative to the vacuum-dried mass. DMAc resolubility was investigated on films before $\mathrm{H}_{2} \mathrm{SO}_{4}$ treatment.

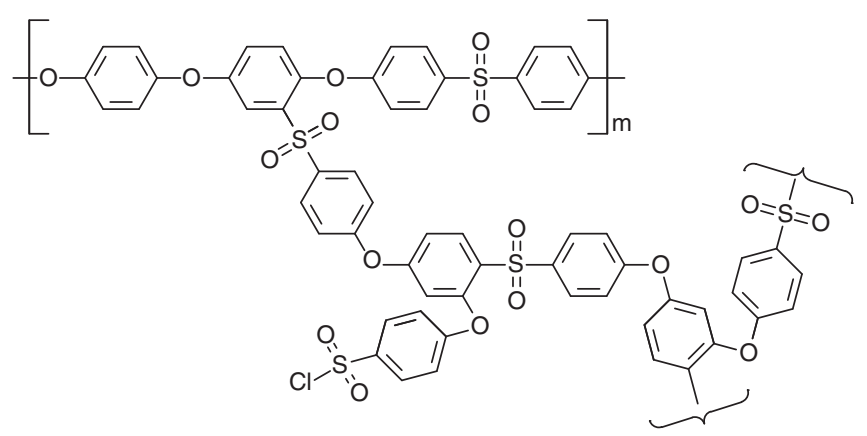

Scheme 2 Desired location for covalently linking the hyperbranched polymer at the phase-phase interface.

polymer film should contain little, if any, DMAc. Thus, we speculated that the sulfonation reaction occurred along the hyperbranched-linear phase boundary, forming a covalent bond. Confirming that such a reaction occurred was difficult because the sulfone bond that was generated during the reaction was not unique to the system and was generated in such a small amount that identification by Fouriertransformed infrared and NMR analyses were inconclusive.

To indirectly verify that tethering occurred, a portion of each of the dried films was further heated in vacuo to temperatures greater than the $\operatorname{Tg}\left(220^{\circ} \mathrm{C}\right)$. For the 20 and $30 \mathrm{wt} \%$ films, only minor changes in the film morphology were observed. Specifically, films containing 20 and $30 \mathrm{wt} \%$ hyperbranched polymer shifted to a slightly more spherical phase structure. Films prepared at 150 or $220^{\circ} \mathrm{C}$ were reintroduced into DMAc. As shown in Table 4, the films that were dried at $150{ }^{\circ} \mathrm{C}$ redissolved within seconds, whereas films heated to $220^{\circ} \mathrm{C}$ swelled and persisted in solution for several weeks indicating that the end groups from the hyperbranched polymer reacted with linear polymer chains to form a crosslinked network. This observation and other indirect measurements suggested that hyperbranched polymer chains became tethered to the structural phase of the linear polymer.

The sulfonyl chloride version of the hyperbranched polymer was not suitable for proton conduction. Methods for converting sulfonyl chloride groups to sulfonic acid, such as heating in hot water, did not produce the desired conversion. During the drying process, a thin film of linear polymer formed at the polymer-air interface, preventing conversion of the sulfonic acid groups. However, the surface of the

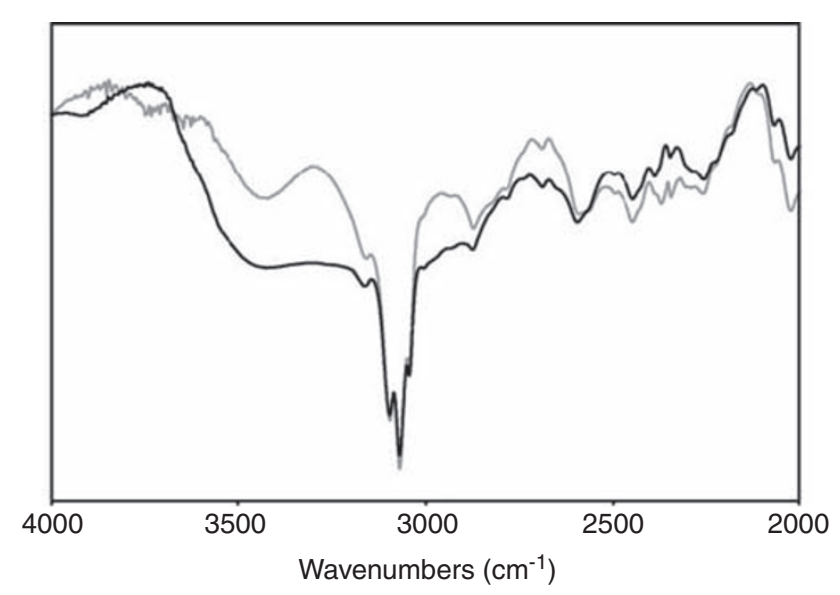

Figure 4 Fourier-transform infrared (FT-IR) spectrum of a $20 w t \%$ hyperbranched film before (gray line) and after (black line) treatment with $16 \mathrm{M} \mathrm{H}_{2} \mathrm{SO}_{4}$ at $50^{\circ} \mathrm{C}$ for $3 \mathrm{~h}$.

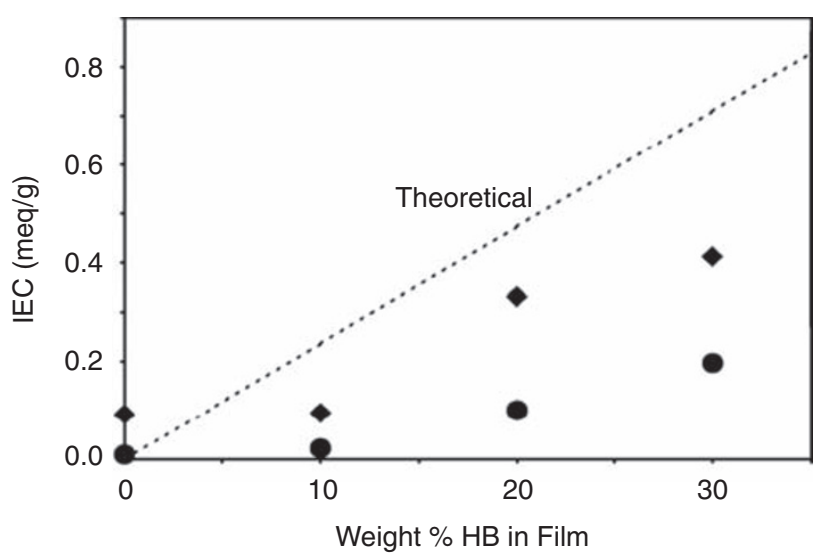

Figure 5 lon-exchange capacity (IEC) of dried blends $(\bullet)$ and cured blends $(\bullet)$ as measured by back titration of $\mathrm{NaOH}$. The dashed line indicates the theoretical IEC based on the amount of HB polymer. Reported values are the average of three samples. The errors associated with the measurement were $< \pm 0.12$.

polymer could be sulfonated with $16 \mathrm{M} \mathrm{H}_{2} \mathrm{SO}_{4}$. Thus, high concentration of sulfuric acid were strong enough to sulfonate the linear polymer at the surface of the film, allowing access to the hyperbranched phase without dissolving the bulk of the polymer. Conversion of the hyperbranched phase from the sulfonyl chloride to the sulfonic acid was confirmed by an increase in the turbidity of the film, which is due to a larger difference in the refractive indices of the two phases. The Fourier-transformed infrared spectra indicated an increase in the peak located in the $\mathrm{OH}$-stretching region, which is consistent with acid formation (Figure 4).

\section{Characterization of hyperbranched-linear PES blend films}

The ion-exchange capacity (IEC) of the films was correlated to the amount of hyperbranched polymer in the film (Figure 5). The $30 \mathrm{wt} \%$ dried film displayed the highest IEC, and values of $0.4 \mathrm{meq}^{-1}$ were obtained. Moreover, the results indicated that heated films possessed lower IEC values than dried films. Compared with the IEC of a Nafion membrane (0.9), the IEC values obtained in this study were relatively low, which suggests that sulfonyl chloride groups were consumed during the additional heating step, causing insolubility in DMAc. 
Additionally, all the samples possessed IEC values that were slightly below the theoretical value, which is based on the complete conversion of the end groups of the hyperbranched polymer to sulfonic acids. The leaching of nontethered hyperbranched polymers, excessive consumption of end groups during tethering, and phase isolation could explain the low IEC values; however, the specific causes have yet to be identified.

The mechanical strength of the films was compared to that of the pure linear polymer (Table 5). The Young's modulus of the blended films was slightly lower (same order of magnitude) than that of the pure polymer, and the yield stress at break was similar. These results suggest that the polymer forms a continuous phase and is not compromised by the presence of the hyperbranched polymer or the effects of sulfonation. The affect of blending and sulfonation increase the elongation of the samples, due to additional strain release modes along phase boundaries. Moreover, in the concerted film, hydrogen bonding/ water uptake can also increase the number of strain release modes.

The proton conductivity of the films was measured according to the four-probe impedance method (Figure 6). Initially, the films were in a dry state and were measured at $80{ }^{\circ} \mathrm{C}$ and $90 \%$ relative humidity. The proton conductivity of the films increased with an increase in the concentration of hyperbranched polymer. With the exception of the $10 \mathrm{wt} \%$ film, the conductivities of the dried films were slightly higher than those of the heated films. However, the relative error of the measurement precludes deeper speculation. All films were slightly lower than the accepted range for Nafion $117\left(0.08-0.10 \mathrm{~S} \mathrm{~cm}^{-1}\right)$; however, the proton conductivities of the films were of the same order

Table 5 Mechanical properties measured by tensile testing

\begin{tabular}{lccc}
\hline Film (content of $\mathrm{HB}$ ) & $\begin{array}{c}\text { Elongation } \\
\text { (\%) }\end{array}$ & $\begin{array}{c}\text { Strength } \\
(\mathrm{MPa})\end{array}$ & $\begin{array}{c}\text { Young's modulus } \\
\text { (GPa m) }\end{array}$ \\
\hline $0 \%$ & 3 & 50.0 & 4.95 \\
10 wt\% cured & 7 & 55.0 & 2.49 \\
10 wt\% cured after $\mathrm{H}_{2} \mathrm{SO}_{4}$ & 29 & 29.9 & 1.83 \\
20 wt\% cured & 7 & 67.5 & 3.95 \\
20 wt\% cured after $\mathrm{H}_{2} \mathrm{SO}_{4}$ & 20 & 41.6 & 3.19 \\
30 wt\% cured & 8 & 39.5 & 2.72 \\
30 wt\% cured after $\mathrm{H}_{2} \mathrm{SO}_{4}$ & 30 & 19.9 & 0.98 \\
\hline
\end{tabular}

Abbreviation: $\mathrm{HB}$, hyperbranch.

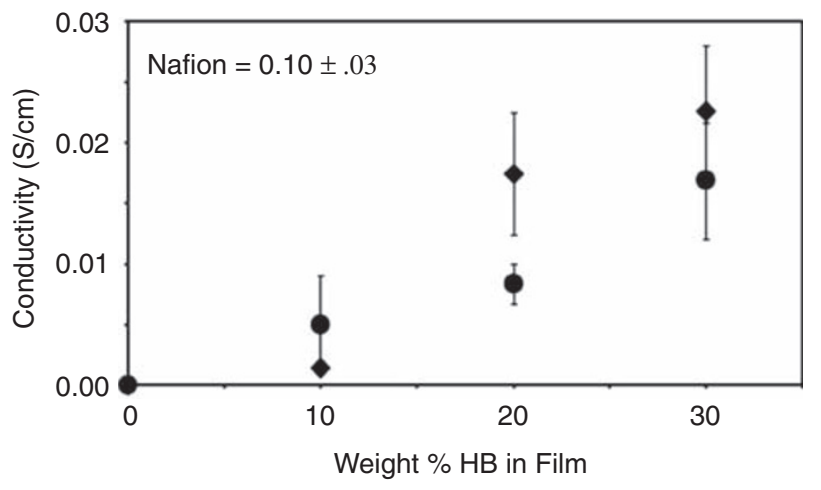

Figure 6 Proton conductivities of dried blends $(\bullet)$ and cured $(\bullet)$ blends, as measured by the four-probe method at $80^{\circ} \mathrm{C}$ and $90 \%$ relative humidity. Reported values are the average of three samples. The proton conductivity of Nafion 117 was obtained under identical conditions. of magnitude. The films may have possessed lower proton conductivities because of a reduced amount of free water within the film. For instance, the films possessed a maximum water uptake of $\sim 7 \%$, whereas Nafion 117 has a maximum water uptake of $18 \%$. Fewer sulfonic acid groups and the separation of the hyperbranched phase into spherical domains (that is, the collapse of the spinodal phase during the drying and heating steps) may have reduced the proton conductivities of the films.

The bicontinuous phase structure of blend membranes makes direct comparisons with more common polyelectrolyte membranes difficult. The acid groups in polyelectrolyte membranes are homogeneously distributed and require water to drive the formation of conduits for proton travel. Alternatively, the acid groups in the proposed membranes are distributed heterogeneously, and the proton conduits are formed by phase separation. The hyperbranched-linear blend membranes contain a small region with a high acid concentration and a large area devoid of acid groups. Thus, even though the IEC and proton conductivity values are low compared with those of the Nafion membrane, these values are a bulk average of the conducting and nonconducting phases. Clearly, the IEC and proton conductivity values of the pure hyperbranched phase are higher. However, to calculate the IEC and proton conductivity values of the pure hyperbranched phase, accurate knowledge of the fraction of hyperbranched polymer removed by leaching, the volume of the noncontinuous (spherical) phase, and the number of end groups that formed bonds the linear polymer must be known. The chemical similarities between the hyperbranched and linear phase, and the ambiguity of the tethering chemistry impede detailed analysis. Ongoing studies are focused on measuring the current density output from a fuel cell assembly, which is a more direct means of assessing the membrane performance of this novel architecture.

The results of this study suggest that hyperbranched polymers could be applied as the proton conduction phase for fuel cell membranes. The robustness of hyperbranched polymers was improved by blending the material with a linear polymer. The phase structure generated during the film-forming process was spinodal and the hyperbranched polymer could be tethered to the linear polymer by $\mathrm{FeCl}_{3}$-catalyzed sulfonation in the solid state to prevent leeching of the hyperbranched phase. The proton conductivities of the blended films are of the same order of magnitude as that of a Nafion membrane. Current studies are focused on reducing the domain size of the spinodal phase, improving water management capabilities, investigating alternate method of tethering the hyperbranched phase to the linear phase, and analyzing the performance of the films in a fuel cell assembly.

\section{CONCLUSION}

In summary, the mechanical deficiencies of sulfonated hyperbranched polymers can be overcome by blending the polymers with a linear structural polymer, and the resulting materials can be used for protonexchange membranes. Care must be taken to induce proper bicontinuous phase formation, which allows the transfer of protons from one side of the membrane to the other. Additionally, care must also be taken to ensure that the sulfonated hyperbranched polymer, which is highly soluble in water, remains within the membrane.

1 As the best review; Tomalia, D. A., Naylor, A. M. \& Goddard III, W. A. Starburst dendrimers: molecular-level control of size, shape, surface chemistry, topology, and flexibility from atoms to macroscopic matter. Angew. Chem. Int. Ed. 29, 138 (1990).

2 Kim, Y. M. Hyperbranched polymers 10 years after. J. Polym. Sci. A Polym. Chem. 36, 1685 (1998). 
3 Voit, B. New developments in hyperbranched polymers. J. Polym. Sci. A Polym. Chem. 38, 2505-2525 (2000).

4 Voit, B. Hyperbranched polymers-all problems solved after 15 years of research? J. Polym. Sci. A Polym. Chem. 43, 2679-2699 (2005).

5 Yang, G., Jikei, M. \& Kakimoto, M. Successful thermal self-polycondensation of AB2 monomer to form hyperbranched aromatic polyamide. Macromolecules 31, 5964-5966 (1998).

6 Yang, G., Jikei, M. \& Kakimoto, M. Synthesis and properties of hyperbranched aromatic polyamide. Macromolecules 32, 2215-2220 (1999).

7 Ishida, Y., Sun, A. C. F., Jikei, M \& Kakimoto, M Synthesis of hyperbranched aromatic polyamides starting from dendrons as ABx monomers: Effect of monomer multiplicity on the degree of branching. Macromolecules 33, 2832-2838 (2000).

8 Jikei, M., Fujii, K., Yang, G. \& Kakimoto, M. Synthesis and properties of hyperbranched aromatic polyamide copolymers from $\mathrm{AB}$ and $\mathrm{AB} 2$ monomers by direct Polycondensation. Macromolecules 33, 6228-6234 (2000).

9 Jikei, M. \& Kakimoto, M. Hyperbranched aromatic polyamides prepared by direct polycondensation. High Perform. Polym. 13, S33-S43 (2001).

10 Jikei, M., Fujii, K. \& Kakimoto, M. Copolymerization behavior of direct polycondensation of $\mathrm{AB} 2$ and $\mathrm{AB}$ monomers that forms hyperbranched aromatic polyamide copolymers. J. Polym. Sci. A Polym. Chem. 39, 3304-3310 (2001).

11 Kaneko, R., Jikei, M. \& Kakimoto, M. Preparation and properties of composite materials composed of hyperbranched aromatic polyamide and vinyl polymers. High Perform. Polym. 14, 41-51 (2002).

12 Kaneko, R., Jikei, M. \& Kakimoto, M. Preparation and properties of photosensitive polymers based on hyperbranched aromatic polyamides. High Perform. Polym. 14, 53-62 (2002).

13 Kaneko, R., Suzuki, E., Jikei, M. \& Kakimoto, M. Preparation and properties of hyperbranched aromatic polyamide-silica composites by sol-gel method. High Perform. Polym. 14, 105-114 (2002).

14 Jikei, M., Fujii, K. \& Kakimoto, M. Synthesis and characterization of hyperbranched aromatic polyamide copolymers prepared from $\mathrm{AB} 2$ and $\mathrm{AB}$ monomers. Macromol. Symp. 199, 223-232 (2003).

15 Jikei, M. \& Kakimoto, M. Dendritic aromatic polyamides and polyimides. J. Polym. Sci. A Polym. Chem. 42, 1293-1309 (2004).

16 Koketsu, T., Kakimoto, M., Jikei, M. \& Kim, S. Y. Synthesis of polyamide dendrons bearing pyridine groups as multiple hydrogen bonding parts on the periphery. Polym. J. 36, 513-518 (2004).

17 Wang, K. L., Inai, Y., Jikei, M. \& Kakimoto, M. Synthesis and properties of different degree of branching polyamides derived from an ABB' type monomer, 4-(2,4-diaminophenoxy) benzoic acid. Polym. J. 36, 804-811 (2004).

18 Kouketsu, T., Yokomachi, K., Kakimoto, M. \& Jikei, M. Synthesis of polyamide dendrimers bearing multiple hydrogen bonding parts on the periphery. High Perform. Polym. 16, 611-624 (2004).

19 Yamanaka, K., Jikei, M. \& Kakimoto, M. Synthesis of hyperbranched aromatic polyimides via polyamic acid methyl ester precursor. Macromolecules 33, 1111-1114 (2000).

20 Yamanaka, K., Jikei, M. \& Kakimoto, M. Preparation and properties of hyperbranched aromatic polyimides via polyamic acid methyl ester precursors. Macromolecules 33, 6937-6944 (2000).

21 Yamanaka, K., Jikei, M. \& Kakimoto, M. Preparation of hyperbranched aromatic polyimide without linear units by end-capping reaction. Macromolecules $\mathbf{3 4}$, 3910-3915 (2001).

22 Yamanaka, K., Jikei, M. \& Kakimoto, M. Syntheses and properties of hyperbranched aromatic polyimides with various end-groups. J. Photopolym. Sci. Tech. 14, 11-16 (2001)

23 Hao, J., Jikei, M. \& Kakimoto, M. Synthesis and comparison of hyperbranched aromatic polyimides having the same repeating unit by $A B 2$ self-polymerization and $A 2+B 3$ polymerization. Macromolecules 36, 3519-3528 (2003).

24 Wang, K. L., Jikei, M. \& Kakimoto, M. Hyperbranched aromatic polyimides from selfpolycondensation of ABB' monomer. J. Photopolym. Sci. Technol. 16, 267-268 (2003).

25 Wang, K. L., Jikei, M. \& Kakimoto, M. Synthesis and soluble branched polyimides derived from an ABB' monomer. J. Polym. Sci.A Polym. Chem. 42, 3200-3211 (2004)

26 Ishida, Y., Jikei, M. \& Kakimoto, M. Synthesis of hyperbranched aromatic polyesters by carbon monoxide insertion reaction using palladium catalyst. Polym. Adv. Technol. 11, 698-704 (2000).

27 Kim, K. M., Jikei, M. \& Kakimoto, M. Preparation and properties of novel hyperbranched poly(dimethylsiloxane). Polym. J. 34, 275-279 (2002).

$28 \mathrm{Kim}$, K. M., Jikei, M. \& Kakimoto, M. Synthesis and properties of amphiphilic hyperbranched poly(dimethylsiloxane) possessing hydrophilic terminal group. Polym. J. 34, 755-760 (2002).

29 Hong, C., Jikei, M. \& Kakimoto, M. Synthesis and characterization of hyperbranched polybenzoxazoles. J. Photopolym. Sci. Technol. 15, 219-222 (2002).

30 Hong, C. S., Jikei, M., Kikuchi, R. \& Kakimoto, M. Chemically amplified photosensitive polybenzoxazoles based on tert-butoxycarbonyl protected hyperbranched poly(o-hydroxyamide)s. Macromolecules 36, 3174-3179 (2003).

31 Hong, C. S., Jikei, M. \& Kakimoto, M. Negative-working photosensitive polybenzoxazoles based on hyperbranched poly(ohydroxyamide)s. Polym. J. 35, 586-591 (2003).

32 Hong, C. S., Jikei, M. \& Kakimoto, M. Synthesis and characterization of hyperbranched polybenzoxazoles via poly (o-hydroxyamide) precursors. Polym. J. 35, 859-867 (2003).

33 Hong,, C. S., Padbanaban, M., Jikei, M. \& Kakimoto, M. Photosensitive polybenzoxazoles based on tert-butoxycarbonyl protected hyperbranched poly(o-hydroxyamide)s,
'Advanced in Image Materials and Processes', Ed. by Horoshi Ito, P. Rao Varanasi,Mahmound M. Khojasteh, Rex Chen Society of Plastics Engineers Mid-Hudson Section 275-278 (2004).

34 Jikei, M., Mori, R., Kawauchi, S., Kakimoto, M. \& Taniguchi, Y. Synthesis and properties of hyperbrnched poly(triphenylamine)s prepared by palladium catalyzed C-N coupling reaction. Polym. J. 34, 550-557 (2002).

35 Takeuchi, M., Jikei, M. \& Kakimoto, M. Preparation of hyperbranched aromatic poly(ethersulfone)s possessing sulfonic acid terminal groups for polymer electrolyte. Chem. Lett. 32, 242-243 (2003).

36 Takeuchi, M., Jikei, M. \& Kakimoto, M. Preparation of composites of hyperbranched aromatic poly(ethersulfone)s possessing sulfonic acid terminal groups and epoxyresin for polymer electrolyte. High Perform. Polym. 15, 219-228 (2003).

37 Grunzinger, S. J., Watanabe, M., Fukagawa, K., Tominaga, Y., Hayakawa, T. \& Kakimoto, M. Coupling of hyperbranched and linear poly(ether sulfone)s in the solid state. J. Photopolym. Sci. Tech. 20, 193-196 (2007).

38 Grunzinger, S. J., Watanabe, M., Fukagawa, K., Kikuchi, R., Tominaga, Y., Hayakawa, T. \& Kakimoto, M. Hyperbranched-linear poly(ether sulfone) blend films for proton exchange membranes. J. Power Sources 175, 120-126 (2008).

39 Grunzinger, S. J., Hayakawa, T. \& Kakimoto, M. Synthesis of multiblock hyperbranched-linear poly(ether sulfone) copolymers. J. Polym. Sci. A Polym. Chem. 46, 4785-4793 (2008).

40 Nogami, K., Kakimoto, M., Hayakawa, T., Yokomachi, K., Seino, M. \& Sakamoto, K. Modification of anodized aluminum film by hyperbranched poly(siloxysilane)s in conductive polymer aluminum solid electrolytic capacitor. Chem. Lett. 35, 134-135 (2006).

41 Seino, M., Hayakawa, T., Ishida, Y. \& Kakimoto, M. Synthesis and characterization of crystalline hyperbranched polysiloxysilane with POSS groups at the terminal position. Macromolecules 39, 8892-8894 (2006).

42 Ishida, Y., Yokomachi, K., Seino, K., Hayakawa, T. \& Kakimoto, M. Synthesis, endfunctionalization and characterization of hyperbranched polysiloxysilanes from AB3 type monomer,. Macromol. Res. 15, 147-153 (2007).

43 Ding, L., Hayakawa, T. \& Kakimoto, M. Synthesis and characterization of hyperbranched poly(siloxysilane) possessing rhodamine B as terminal group. Polym. J. 39, 551-557 (2007).

44 Yamada, Y., Hirai, T., Kikuchi, R., Hayakawa, T. \& Kakimoto, M. Adsorption of hyperbranched polysiloxysilane modified with triethoxy group onto the silicon wafer. High Perfom. Polym. 18, 761-775 (2007).

45 Yokomachi, K., Seino, M., Grunzinger, S. J., Hayakawa, T. \& Kakimoto, M. Synthesis and degree of branching of epoxy-terminated hyperbranched polysiloxysilane. Polym. J. 40, 198-204 (2008).

46 Jikei, M., Chou, S. H., Kakimoto, M., Kawauchi, S., Imase, T. \& Watanabe, J. Synthesis of hyperbranched aromatic polyamide from aromatic diamines and trimesic acid. Macromolecules 32, 2061-2064 (1999).

47 Hao, J., Jikei, M. \& Kakimoto, M. Preparation of hyperbranched aromatic polyimide via A2+B3 approach. Macromolecules 35, 5372-5381 (2002).

48 Hao, J., Jikei, M. \& Kakimoto, M. Hyperbranched polyimides prepared by ideal A2+B3 polymerization, non-ideal $\mathrm{A} 2+\mathrm{B} 3$ polymerization and $\mathrm{AB} 2$ self-polymerization. Macromol. Symp. 199, 233-241 (2003).

49 Li, L., Kikuchi, R., Jikei, M., Takahashi, A. \& Kakimoto, M. Synthesis and characterization of new polyimides containing nitrile groups. High Perform. Polym. 17, 135-147 (2005).

50 Takahashi, A., Kakimoto, M., Tsurumi, T., Hao, J., Li, L., Kikuchi, R., Miwa, T., Oono, T. \& Yamada, S. High dielectric ceramic nano particle and polymer composites for embedded capacitor. J. Photopolym. Sci. Tech. 18, 297-300 (2005).

51 Li, L., Takahashi, A., Hao, J., Kikuchi, R., Hayakawa, T., Tsurumi, T. \& Kakimoto, M. Novel polymer-ceramic nanocomposite based on new concepts for embedded capacitor application(I). IEEE Transactions on Components and Packaging Tech. 28, 754-759 (2005).

52 Kakimoto, M., Takahashi, A., Tsurumi, T., Hao, J., Li, L., Kikuchi, R., Miwa, T., Oono, T. \& Yamada, S. Polymer-ceramic nanocomposites based on new concepts for embeded capacitor. Mater. Sci. Eng. B 132, 74-78 (2006).

53 Takahashi, A., Kakimoto, M., Tsurumi, T., Hao, J., Li, L., Kikuchi, R., Miwa, T., Ohno, T., Yamada, S. \& Takezawa, Y. Polymer-ceramic nanaocomposites based on new concepts for embedded capacitor. IEEJ Trans. FM 126, 1160-1166 (2006).

54 Kwon, Y., Hayakawa, T. \& Kakimoto, M. Synthesis of copper phthalocyanine-containing hyperbranched polymer starting from 1,2-bis(3,4-dicyanophenoxy)benzene and CuCl. Chem. Lett. 1306-1307 (2006)

55 Guo, M., Yan, X., Kwon, Y., Hayakawa, T., Kakimoto, M. \& Goodson III, T. High frequency dielectric response in a branched phhalocyanine. J. Am. Chem. Soc. 128, 14820-14821 (2006).

56 Lee, T. W., Kwon, Y., Hayakawa, T., Park, J. J., Pu, L. \& Kakimoto, M. Novel hyperbranched phthalocyanine as a hole injection nanolayer in organic light-emitting diodes. Macromol. Rapid Commun. 28, 1657-1662 (2007).

57 Lee, T. W., Park, J. J., Kwon, Y., Hayakawa, T., Choi, T. L., Park, J. H., Das, R. R. \& Kakimoto, M. Spin-assembled nanolayer of a hyperbranched polymer on the anode in organic light-emitting diodes: the mechanism of hole injection and electron blocking. Langmuir 24, 12704-12709 (2008).

58 Jikei, M. \& Kakimoto, M. Hyperbranched polymers: a promising new class of materials. Prog. Polym. Sci. 26, 1233-1285 (2001).

59 Ueda, M. Synthesis of poly(phenylene ether sulfone) by direct self-polycondensation of sodium 4-phenoxybenzenesulfonate using phosphorus pentoxide/methanesulfonic acid as condensing agent and solvent. Makromol. Chem., Rapid Commun. 6, 271 (1985). 
60 Matsumoto, K. \& Ueda, M. Synthesis of hyperbranched aromatic poly(ether sulfone) with sulfonyl chloride terminal groups,. Chem. Lett. 35, 1196-1197 (2006).

61 Gao, C. \& Yan, D. Hyperbranched polymers: from synthesis to applications. Prog. Polym. Sci. 29, 183-275 (2004).

62 Hirao, A., Hayashi, M., Loykulnant, S., Sugiyami, K., Ryu, S. W., Haraguchi, N., Matsuo, A. \& Higashihara, T. Precise syntheses of chain-multi-functionalized polymers, star-branched polymers, star-linear block polymers, densely branched polymers, and dendritic branched polymers based on iterative approach using functionalized 1,1diphenylethylene derivatives. Prog. Polym. Sci. 30, 111-182 (2005).

63 Unal, S. \& Long, T. E. Highly branched poly(ether ester)s via cyclization-free melt condensation of $A_{2}$ oligomers and $B_{3}$ monomers. Macromolecules 39, 2788-2793 (2006).

64 McKee, M. G., Park, T., Unal, S., Yilgor, I. \& Long, T. E. Electrospinning of linear and highly branched segmented poly(urethane urea)s. Polymer 46, 2011-2015 (2005).

65 Ishizu, K. \& Ochi, K. Architecture of starblock copolymers consisting of triblock arms via a $N, N$-diethyldithiocarbamate-mediated living radical photo-polymerization and application for nanocomposites by using as fillers. Macromolecules 39, 3238-3244 (2006).

66 Kreutzer, G., Ternat, C., Nguyen, T. Q., Plummer, C. J. G., Manson, J- A. E., Castelletto, V., Hamley, I. W., Sun, F., Sheiko, S. S., Herrmann, A., Ouali, L., Sommer, H., Fieber, W., Velazco, M. I. \& Klok, H- A. Water-soluble, unimolecular containers based on amphiphilic multiarm star block copolymers. Macromolecules 39, 4507-4516 (2006).

67 Magnusson, H., Malmstrom, E. \& Hult, A. Synthesis of hyperbranched aliphatic polyethers via cationic ring-opening polymerization of 3-ethyl-3-(hydroxymethyl)oxetane. Macromol. Rapid Commun. 20, 453-457 (1999).

68 Istratov, V., Kautz, H., Kim, Y. K., Schubert, R. \& Frey, H. Linear-dendritic nonionic poly(propylene oxide)-polyglycerol. Tetrahedron 59, 4017-4024 (2003).

69 An, S. G. \& Cho, C. G. Synthesis and characterization of dumbbell type amphiphilic block copolymers via ATRP. Polym. Bull. 51, 255-262 (2004).

70 Kwak, S.- Y., Ahn, D. U., Choi, J., Song, H. J. \& Lee, S.- H. Amelioration of mechanical brittleness in hyperbranched polymer. 1. Macroscopic evaluation by dynamic viscoelastic relaxation. Polymer 45, 6889-6896 (2004).

71. Fanghond, G., Tang, H. Liu, C., Jiang, B., Ren, Q. \& Yang, Y. Preparation of hyperbranched polymers through ATRP of in situ formed $\mathrm{AB}^{*}$ monomer. J Appl. Polym. Sci. 101, 850-856 (2006).

72 Zhu, X., Chen, L., Yan, D., Chen, Q., Yao, Y, Xiao, Y, Hou, J. \& Li, J. Supramolecular self-assembly of inclusion complexes of a multiarm hyperbranched polyether with cyclodextrins. Langmuir 20, 484-490 (2004).
73 Nomura, R., Matsuno, T. \& Endo, T. Synthesis and polymerization of a self-condensable macromonomer. Polym. Bull. 42, 251-256 (1999).

74 Yamada, B., Konosu, O., Tanaka, K. \& Oku, F. Preparation of branched polymer by radical polymerization using polymerizable chain transfer agent. Polymer 41, 5625-5631 (2000).

75 Trollsas, M., Kelly, M. A., Claesson, H., Seimens, R. \& Hedrik, J. L. Highly branched block copolymers: design, synthesis, and morphology. Macromolecules 32 4917-4924 (1999).

76 Peleshanko, S., Gunawidjaja, R., Petrash, S. \& Tsukruk, V. V. Synthesis and interfacial behavior of amphiphilic hyperbranched polymers: poly(ethylene oxide)polystyrene hyperbranches. Macromolecules 39, 4756-4766 (2006)

77 Souzy, R., Ameduri, B., Boutevin, B., Gebel, G. \& Capron, P. Functional fluoropolymers for fuel cell membranes. Solid State lonics 176, 2839-2848 (2005).

78 Eikerling, M., loselevich, A. S. \& Kornyshev, A. A. How good are the electrodes we use in PEFC? Fuel Cells 4, 131-140 (2004).

79 Shimizu, T., Momma, T., Mohamed, M., Osaka, T. \& Sarangapani, S. Design and fabrication of pumpless small direct methanol fuel cells for portable applications. J. Power Sources 137, 277-283 (2004).

80 Kim, W.- J., Choi, H.- G., Lee, Y.- K., Nam, J.- D., Cho, S. M. \& Chung, C.- H. Suppression of the methanol crossover by hydrogels in passively operated flat-pack type DMFCs and its application for the power source of cellular phone. J. Power Sources 163, 98-102 (2006)

81 Deluca, N. W. \& Elabd, Y. A. Polymer electrolyte membranes for the direct methanol fuel cell: a review. J. Polym. Sci. B Poym. Phys. 44, 2201-2225 (2006).

82 Gileadi, E. \& Kirowa-Eisner, E. Electrolytic conductivity -the hopping mechanism of the proton and beyond. Electrochim. Acta 51, 6003-6011 (2006).

83 Choi, P., Jalani, N. H., Thampan, T. M. \& Datta, R. Consideration of thermodynamic, transport, and mechanical properties in the design of polymer electrolyte membranes for higher temperature fuel cell operation. J. Polym. B Polym. Phys. 44, 2183-2200 (2006).

84 Young, A. M., Timbo, A. M., Higgins, J. S., Peiffer, D. G. \& Lin, M. Y. Thermodynamics of aggregation in associating ionomer solutions. Polymer 37, 2701-2708 (1996).

85 Baglio, V., Blasi, D. A., Arico, A. S., Antonucci, V., Antonucci, P. L., Trakanprapai, C., Esposito, V., Licoccia, S. \& Traversa, E. Composite mesoporous titania Nafion-based membranes for direct methanol fuel cell operation at high temperature. J. Electrochem. Soc. 152, A1373-A1377 (2005).

86 Wang, F., Hickner, M., Kim, Y. S., Zawadzinski, T. A. \& McGrath, J. E. Direct polymerization of sulfonated poly(arylene ether sulfone) random (statistical) copolymers: candidates for new proton exchange membranes. J. Membr. Sci. 197, 231-242 (2002).

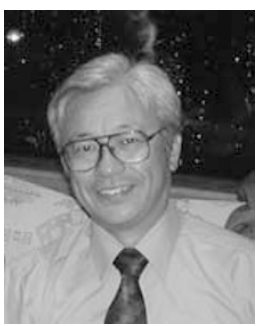

Masa-aki Kakimoto received his BS (1975) degree from Yamaguchi University in the group of Professor Shuji Kanemasa, and MS (1977), PhD (1980) degrees from Tokyo Institute of Technology in the group of Professor Makoto Okawara. In 1980, he joined Sagami Central Research Center. He moved to Tokyo Institute of Technology, working with Professor Yoshio Imai as Assistant Professor in 1982. He was promoted to a full Professor in 1997. He received the Ichimura Award in 1996, Award in The Society of Fiber Science and Technology in 2000, and the Mitsubishi Chemical Award of the Society of Polymer Science, Japan, in 2009. His current research interests are in the design and synthesis of dendritic macromolecules, and development of carbon alloy catalysts for fuel cells. 